\title{
Support Technology of Long Bolt in Roadway underCrushing Condition
}

\author{
Sang Pengde \\ China Coal Science \& Industry Group Taiyuan Research Institute Co., LTD., Taiyuan, Shanxi 030006, China
}

\begin{abstract}
In order to solve the problem that the roadway roof is large and easy to collapse under crushing conditions. Test shows that: Under the crushing condition, a considerable part of roadway surrounding rock deformation is in a given deformation state. The control effect of support resistance on surrounding rock deformation is limited at the level of existing technology. In this kind of roadway support, the deformation method of anchor cable high rigidity support should be abandoned. It is changed to adopt the long bolt with high elongation to adapt to the deformation of surrounding rock, and continue to provide high support resistance to prevent loose rock caving caused by roof collapse. Based on this, the supporting technology of replacing anchor cable with docking bolt is put forward to increase the coordination between supporting member and roadway surrounding rock deformation. The industrial test results of Baode coal mine show that the technology can adapt to the deformation of surrounding rock and effectively prevent the tunnel roof from caving due to the break of anchor cable.
\end{abstract}

\section{Introduction}

For a long time, the main strategy for roadway support under such crushing conditions is to continuously strengthen the support strength, in an attempt to increase the rigidity of the roadway roof ${ }^{[1]}$, but the results show that the control effect of this roadway is not ideal, a large number of anchor cable failure phenomenon still exists, roadway roof accidents occur from time to time ${ }^{[2]}$.

In order to solve this problem, this paper proposes a practical new technology to replace the anchor cable with the butt bolt, that is, the butt bolt with a length of $5 \mathrm{~m}$ is used to replace the anchor cables of various diameters in the roadway under the crushing condition that the roadway roof is sinking up to $300-1500 \mathrm{~mm}$. It makes the rigid anchoring of anchor cable to roof become the flexible anchoring of long bolt to roof, increases the coordination of deformation between supporting member and roadway surrounding rock, and achieves the purpose of basically eliminating the hidden danger of anchorage member breaking and roof caving.

\section{General situation and test plan of test roadway}

Baode coal mine of Shendong Coal Company is located in Baode county, Shanxi Province. The main coal seam of this mine is No. 8 coal seam with a depth of about $400 \mathrm{~m}$. The roof of the coal seam is mostly sandy mudstone ${ }^{[3]}$, partially coarse sandstone, and the floor is mainly mudstone, as shown in Fig. 1. Among them, the roof rock layer has a large range of variation, the thickness of unstable rock layer is large, and the internal cracks are developed in the roof, and the unidirectional compressive strength is mostly in the range of 10-30mpa. The roof stability is poor. When the reserved roadway is moved by the adjacent working face, the roof sinks violently (Fig. 2). In some areas, the roof sinks more than $1000 \mathrm{~mm}$ or even $1320 \mathrm{~mm}^{[4]}$. 


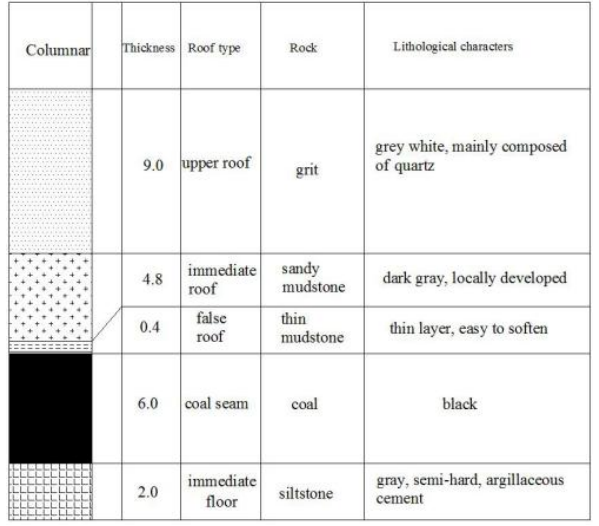

Fig. 1 Column diagram of roof and floor of coal seam

In order to control the severe deformation of the roadway roof and prevent roof collapse, the industrial tests of different support strength and butt-bolt replacing anchor cable support were carried out in the return wind channel of Baode mine through secondary reinforcement ${ }^{[5]}$. The three different supporting strengths of roof are $0.272 \mathrm{mpa}, 0.424 \mathrm{mpa}$ and $0.548 \mathrm{mpa}$

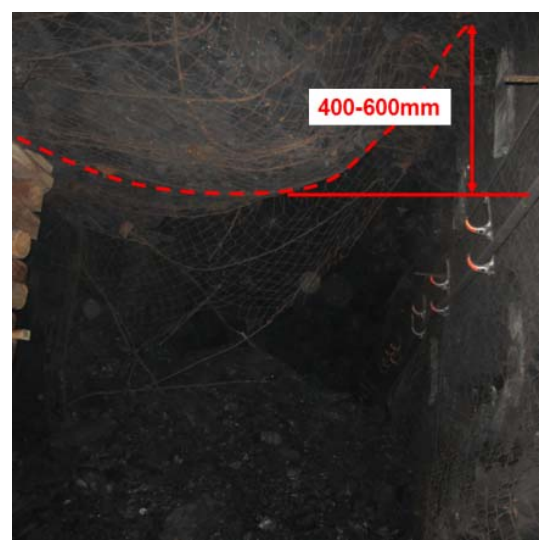

Fig. 2 Severe roof deformation and failure during secondary mining

respectively, and the length of each scheme is $100 \mathrm{~m}$, as shown in Fig. 3.

Roadway supporting parameters on the roof of the original test for 2 root $\Phi 17.8 \times 6500 \mathrm{~mm}$ anchor bolt and $4 \operatorname{root} \Phi 20 \times 2200 \mathrm{~mm}$, the test after the second reinforcement scheme of the support strength and reinforcement parameters (Fig. 4), respectively:

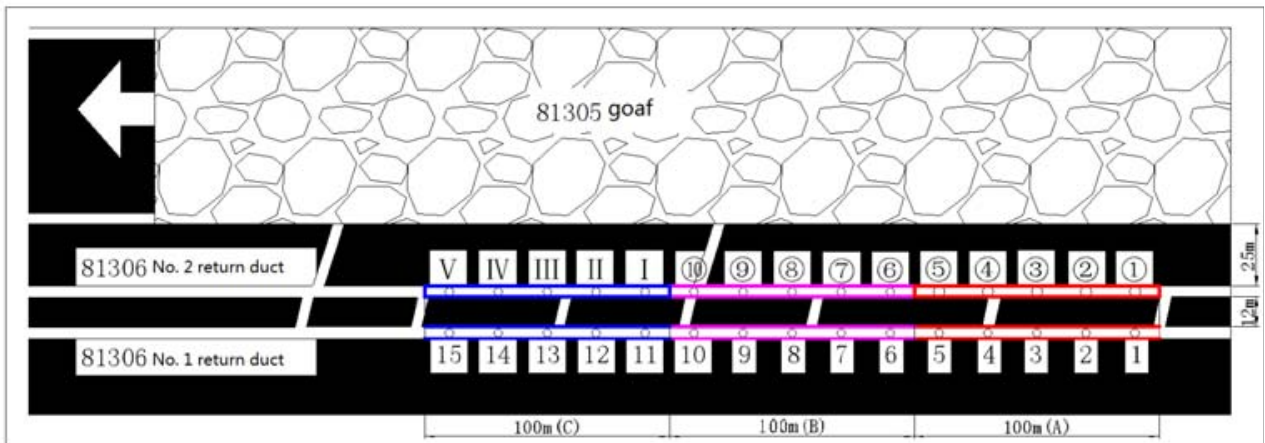

Fig.3 Comparison test diagram of Baode Coal Mine

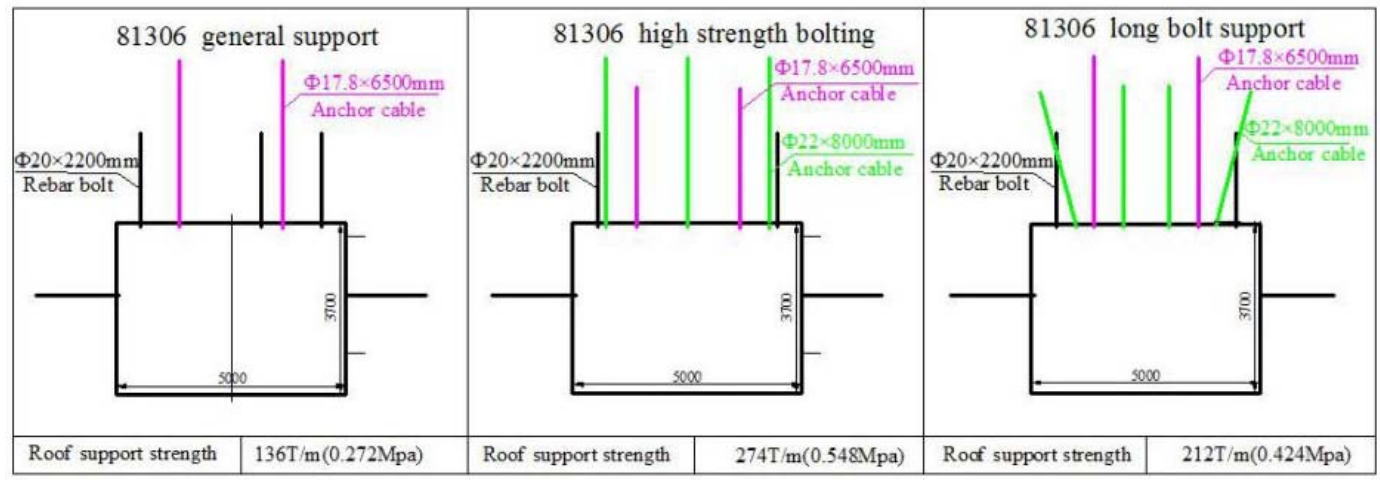

Fig. 4 Roof support test scheme

\section{Cable breaking, roof sinking, roof caving}

\subsection{Relationship between cable breaking and roof sinking}

For roadway anchor wire breakage situation has carried on the statistical test, see table 1, A section of the roadway $\Phi 17.8$ cable breakage rate $58.5 \%$; B section of the roadway $\Phi$ anchor cable breakage rate is $64.5 \%, 17.8$ $\Phi 22$ cable breakage rate $14.7 \%$; C section of the roadway $\Phi 17.8$ anchor cable breakage rate is $35 \%$, long bolt breaking rate was $1.75 \%$. As shown in Fig. 5, when the roof subsidence reaches $100 \mathrm{~mm}$, a few anchor cables will break. When the roof subsidence exceeds $300 \mathrm{~mm}$, the cable breakage rate will increase significantly. When the roof subsidence exceeds $600 \mathrm{~mm}$, the cable breakage rate will exceed $70 \%$. The breaking rate of anchor cable is positively correlated with the sinking amount of roof, and the larger the sinking amount of roof, the higher the breaking rate of anchor cable ${ }^{[6]}$. 
Tab. 181306 Statistics of roof sinking and anchor bolt (cable) breaking in test section of return air channel

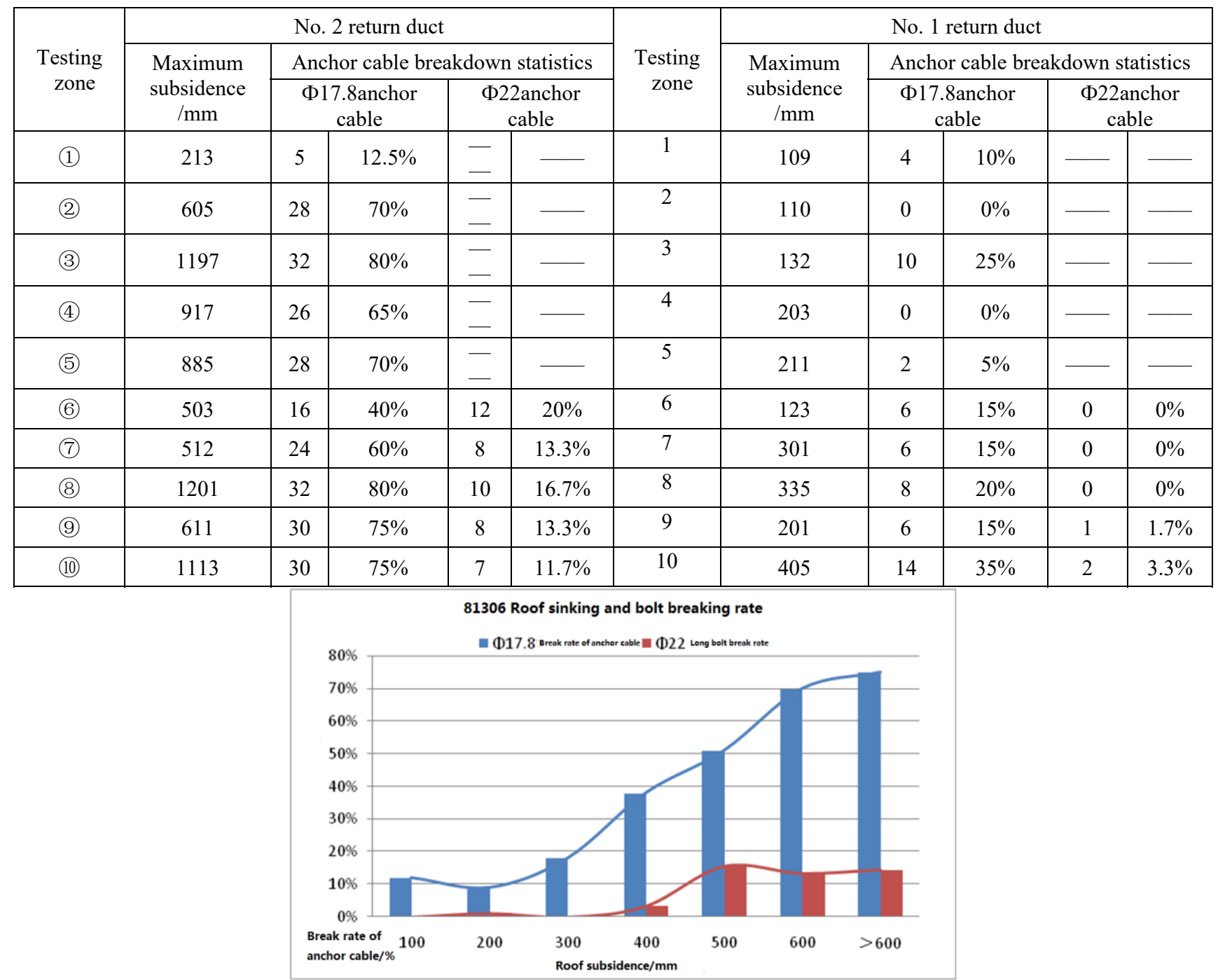

Fig. 5 Relation between roof subsidence and anchor cable break rate

\subsection{Cable breaking mechanism and failure form}

The load-bearing capacity and elongation capacity of the anchor cable are two important indexes reflecting the performance of the anchor cable. Literature [7] studies the engineering breaking load and engineering elongation of the anchor cable, as shown inTable 2.

Table 2 Mechanical parameters of anchor cable

\begin{tabular}{|c|c|c|c|c|}
\hline $\begin{array}{c}\text { Anchor cable } \\
\text { diameter/mm }\end{array}$ & $\begin{array}{c}\text { Strength grade of } \\
\text { steel strand }\end{array}$ & $\begin{array}{c}\text { Theoretical breaking } \\
\text { load/kN }\end{array}$ & Engineering breaking load/kN & elongation \\
\hline 15.24 & 1860 & 260 & 221 & $3.5 \%$ \\
\hline 17.8 & 1860 & 355 & 301 & $3.5 \%$ \\
\hline 21.6 & 1860 & 539 & 458 & $3.5 \%$ \\
\hline
\end{tabular}

This paper selected the length is $4000 \mathrm{~mm} \Phi 20$ long bolt, $\Phi 17.8$ anchor cable, $\Phi 15.24$ anchor cable, which three kinds of support materials were tested for their elongation. The results showed that $\Phi 17.8$ anchor cable maximum extension length of $4000 \mathrm{~mm}$ is to 135 $\mathrm{mm}$, elongation is $3.37 \%$. $\Phi 15.24$ anchor cable maximum extension length is $125 \mathrm{~mm}$, elongation is
$3.13 \%$. $Ф 20$ long bolt maximum extension length is $685 \mathrm{~mm}$, long bolt elongation is $17.12 \%$. The extension capacity of the bolt is much greater than that of the cable. $\Phi 20$ long bolt elongation is 5.07 times to $\Phi 17.8$ anchor cable, and 5.48 times to $\Phi 15.24$ anchor cable, as shown in Fig. 6. 


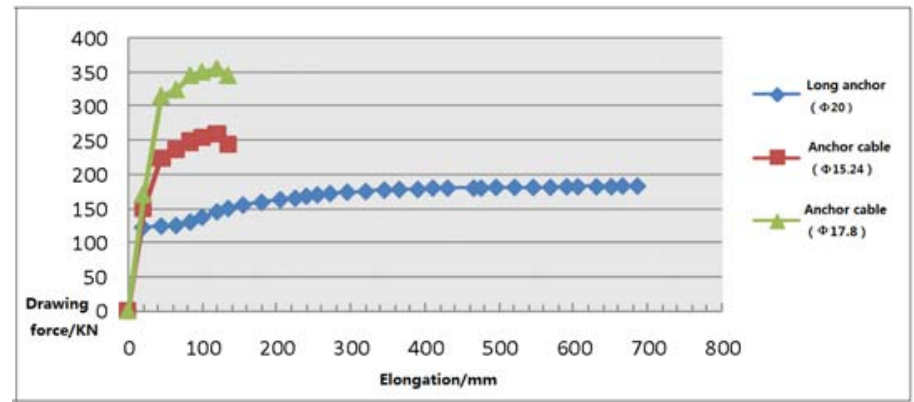

Fig. 6 Tensile test curve of anchor cable bolt

According to the previous analysis, the roof subsidence of the broken roadway is more than $300 \mathrm{~mm}$, which exceeds the elongation capacity of the anchor cable. The anchor cable is unable to resist and adapt to the deformation of surrounding rock, so it fails and is damaged. Failure modes of anchor cable include: the anchorage failure of the anchor cable and surrounding rock is pulled out, the elongation ability of the anchor cable is low and broken by various factors, and the stress of the local roof at the end of the anchor cable is too concentrated, resulting in the fracture and roof leakage, as shown in Fig. 7.

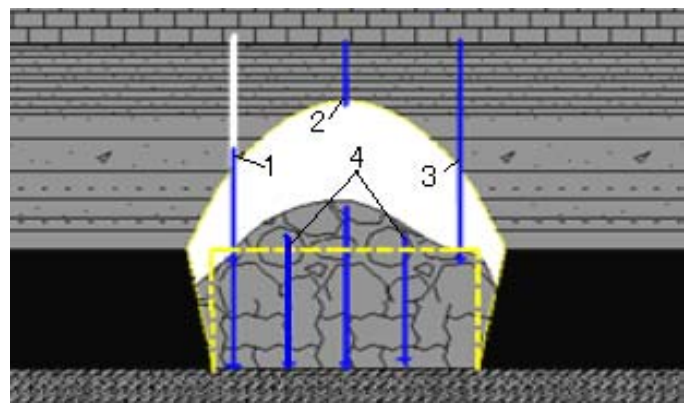

1-Anchor fails and is pulled out;2-Anchor rope breakage;3-The end of the anchor rope is drawn into the roof;4-Bolt length is less than loose body height

Fig. 7 Failure diagram of anchor cable

\section{Supporting countermeasures of roadway under crushing conditions}

In Baode coal mine, the field comparison test of long bolt and anchor cable is carried out, and the test results show that: under the condition of consistent roof subsidence, the breaking rate of anchor cable is much higher than that of long bolt. When the roof subsidence is $200 \mathrm{~mm}$, the break rate of anchor cable reaches $10 \%$. The breaking rate of the long bolt is only $1 \%$, the difference is 10 times. When the roof subsidence is more than $600 \mathrm{~mm}$, the break rate of anchor cable reaches $75 \%$. The break rate of the long bolt is $3 \%$, which is more than 20 times. In the roadway with large deformation, the butt long bolt can adapt to the large deformation of surrounding rock, overcome the shortcomings of low elongation of anchor cable and failure of surrounding rock after deformation, and eliminate the hidden danger of roof caving, as shown inTable 2 and Fig. 8.

Tab 3 statistics of roof sinking and anchor bolt (cable) breaking in the test section of return air channel

\begin{tabular}{|c|c|c|c|c|c|c|c|c|c|c|c|}
\hline \multirow{4}{*}{$\begin{array}{c}\text { Testin } \\
\text { g } \\
\text { zone } \\
\text { I }\end{array}$} & \multicolumn{5}{|c|}{ No. 2 return duct } & \multirow{4}{*}{$\begin{array}{c}\text { Testin } \\
\text { g } \\
\text { zone }\end{array}$} & \multicolumn{5}{|c|}{ No. 1 return duct } \\
\hline & \multirow{2}{*}{$\begin{array}{c}\text { Maximum } \\
\text { subsidence } \\
\text { /mm }\end{array}$} & \multicolumn{4}{|c|}{ Anchor cable breakdown statistics } & & \multirow{3}{*}{$\begin{array}{c}\begin{array}{c}\text { Maximum } \\
\text { subsidence } \\
\text { /mm }\end{array} \\
103\end{array}$} & \multicolumn{4}{|c|}{ Anchor cable breakdown statistics } \\
\hline & & \multicolumn{2}{|c|}{$\begin{array}{c}\text { Ф17.8anchor } \\
\text { cable }\end{array}$} & \multicolumn{2}{|c|}{$\begin{array}{c}\text { Ф20anchor } \\
\text { cable }\end{array}$} & & & \multicolumn{2}{|c|}{$\Phi 17.8$ anchor cable } & \multicolumn{2}{|c|}{$\begin{array}{c}\begin{array}{c}\Phi 20 \text { anchor } \\
\text { cable }\end{array} \\
\end{array}$} \\
\hline & 506 & 18 & $45 \%$ & 0 & $0 \%$ & & & 2 & $5 \%$ & 0 & $0 \%$ \\
\hline II & 512 & 22 & $55 \%$ & 1 & $1.25 \%$ & 12 & 155 & 6 & $15 \%$ & 0 & $0 \%$ \\
\hline III & 873 & 30 & $75 \%$ & 1 & $1.25 \%$ & 13 & 307 & 6 & $15 \%$ & 0 & $0 \%$ \\
\hline IV & 611 & 28 & $70 \%$ & 0 & $0 \%$ & 14 & 401 & 16 & $40 \%$ & 0 & $0 \% \%$ \\
\hline $\mathrm{V}$ & 1221 & 30 & $75 \%$ & 3 & $3.75 \%$ & 15 & 231 & 4 & $10 \%$ & 1 & $1.25 \%$ \\
\hline
\end{tabular}




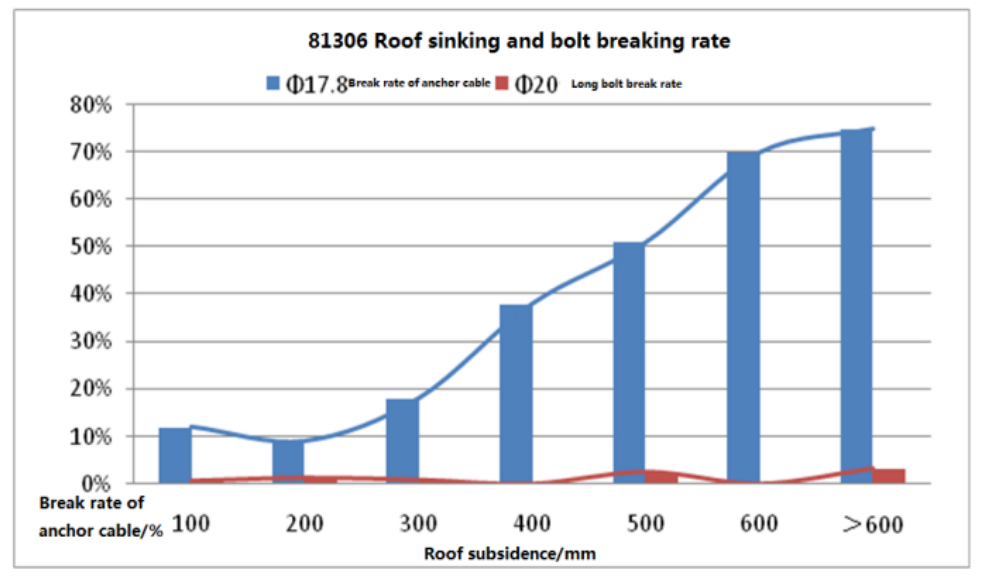

Fig. 8 Relation between roof subsidence and bolt cable break rate

\section{Conclusion}

(1) Under the crushing condition, a considerable part of the deformation of roadway surrounding rock is a "given deformation". Mainly affected by the non-uniformity of mining stress and the spatial difference of roadway surrounding rocks. Under the current technical conditions, the support resistance has limited effect on controlling the deformation of the surrounding rock.

(2) The break rate of anchor cable is positively correlated with the roof subsidence. The larger the roof subsidence is, the higher the break rate of anchor cable will be. After the roof subsidence exceeds $300 \mathrm{~mm}$, the break rate of anchor cable will be more than $50 \%$, even up to $70 \%$.

(3) Under the broken condition, the roadway adopts the support technology of docking long bolt instead of anchor cable to increase the coordination between support members and deformation of roadway surrounding rock. The docking bolt has a more reasonable elongation than the anchor cable, which can coordinate deformation with the surrounding rock and continuously provide support resistance. This technology can overcome the shortcomings of low elongation of anchor cable and failure of surrounding rock after deformation, eliminate the hidden danger of roof caving, and provide a new method for controlling large deformation surrounding rock under broken condition.

\section{Acknowledgements}

Fund project: Experimental study on micro - disturbance mechanical rock excavation engineering technology (M2020-QN09).

\section{Author profile}

Sang Pengde (1985-), male, from liaocheng in shandong province, mining engineer, master, graduatedfrom China University of Mining and Technology (Beijing) in 2011, majoring in mining engineering. Email: sangpengde2008@126.com
1. Hou Zhaojiong team. Roadway Surrounding Rock Control [M]. Xuzhou: China University of Mining and Technology Press, 2013.

2. Zhang yongan, Xie xiaoping. Reasonable Support Technology for Soft Coal Roadway under Difficult Geological Conditions [J]. Coal Mine Safety, 2013,02:96-99.

3. Wei xiujun. Roadway Support under Complex Crushing Conditions $[\mathrm{J}]$. Coal Science and Technology, 2002, 08:31-33+41.

4. Zhang Chengjun, Wu Yingzheng, Zhu Xiaowei. Full Anchor Cable Support Technology for Weak Roof Roadway in Stress Abnormal Area [J]. Coal Science and Technology, 2012, 06:8-11.

5. Chen Shihai, Qiao Weigo, Kong Desen. Research on Application of Bolt-wire Mesh Support Technology in Soft Rock Roadway of Daxing Coal Mine [J]. Rock and Soil Mechanics, 2006, S2:902-904.

6. Qian Minggao, Shi Pingwu. Mine Pressure and Rock Formation control [M]. Xuzhou: China University of Mining and Technology Press, 2003.

7. Zhao Qingbiao, Research on the Synergetic Mechanism of Bolt and Cable in Coal Roadway in Shenjing Broken Surrounding Rock [D]. China University of Mining and Technology (Beijing), 2003.

\section{References}

